\title{
Effective Financial Management of Supply Chain through the Use of Emerging Technology
}

\author{
Abdullah Mohammed Aldakhil ${ }^{1}$ \\ ${ }^{1}$ Department of Management, College of Business Administration, King Saud University, Riyadh, Kingdom of Saudi \\ Arabia \\ Correspondence: Abdullah Mohammed Aldakhil, Assistant Professor, Department of Management, College of \\ Business Administration, King Saud University, Riyadh, Kingdom of Saudi Arabia.
}

Received: December 28, 2015

Accepted: January 6, $2016 \quad$ Online Published: January 18, 2016

doi:10.5430/ijfr.v7n1p189

URL: http://dx.doi.org/10.5430/ijfr.v7n1p189

The researchers would like to thank the Deanship of Scientific Research at King Saud University represented by the Research Centre in the College of Business Administration for financially supporting this research.

\begin{abstract}
In today's globalization business world, the contemporary organizations are flourishing to apply the innovative as well as modern business techniques in order to enhance their supply chain management practices. Moreover, the organizations give ample importance while developing their business strategies to use backward integration strategies along with their other main strategies. There are many emerging technologies available as an option for the organization now days; however, for the purpose of this paper Information Technology (IT) use along with the financial management of supply chain is discussed as a general. It is believed that, effective use of IT might facilitate both the efficiency and transparency of communication amongst the different nodes of supply chain; furthermore, it will enable the organizations to save their costs and effectively manage the finances. This paper builds a conceptual model of IT use, information sharing, and supply chain practices (SCPs) and how the impact on SCPs might affect the level of competitive advantage. Specifically, this paper hypothesized the impact of IT use and information sharing on supply chain management success related to the level of competitive advantage. Furthermore, the paper also hypothesized on the basis of resource-based view of the firm, the effective use of IT and the active information sharing might enhance the supply chain performance and might increase the level of competitive advantages for the organizations.
\end{abstract}

Keywords: supply chain, information technology, competitive advantage

\section{Introduction}

In this knowledge society, where the innovations are occurring at rapid pace and there organizations are restructuring themselves in order to compete in the business world. At the era of innovations, one cannot forget the role of emerging technologies in fostering the innovations. The use of information technology in the business world as an emerging technology or may be perhaps a mature technology is still considered as important for organizational and strategic operations of the organizations. The organizations are undergoing major changes with the use of different information technology (IT) techniques, for example cloud computing (Dothang Truong, 2015). The use of any emerging technology is directly linked to cost reduction which will lead towards enhancing the competitive advantage of the firm (Hong, K.K. and Kim, Y.G., 2002). Cost reductions, in general, help further support utilization of IT and improve management's activities related to monitoring, controlling, and designing business activities. In effect, the more management is involved with IT use, the more likely they are to incorporate IT use in strategy planning formulation, reduction of bullwhip effect, as well as developing competitive advantage. Such an array of IT use reflects applications that can be focused either internally, externally, or both. IT use directly reflects the potential for absorptive capacity within a firm, and the organization's ability to assimilate it, along with movement of knowledge both within the organization, as well as outside the firm, such as suppliers in the supply chain.

Absorptive capacity within a firm tends to bind IT managers and line managers both within a firm, as well as along a supply chain (Henderson, 1990). It has been posited that extensive knowledge overlap and information exchanges 
among managers are directly related to a firm's ability to use IT (V. Botta-Genoulaza, P.-A. Milleta and B. Grabotb 2005). Dell offers a good example in the use of information sharing to enhance supply chain performance practices. Order information is received at the firm's website, either by in-house associates, or directly from customers. The interaction between Dell and customers improves the pull production system which facilitates supply chain planning. To enhance turnaround of product, and meet customer demand, Dell immediately shares relevant information with suppliers. Consequently, the order becomes to both suppliers and customers. Flexibility improvement can be significant with information sharing because this feature both enhances customer service and makes the supply chain partners more responsive. Based on these arguments, the research paper conceptually examines the developments in supply chain practices by effective IT use and its impact on financial benefits for the firm, which will ultimately lead to gain the competitive advantage.

\section{Literature Review}

A Supply Chain is comprised of "a system of suppliers, manufacturers, distributors, retailers, and customers where material, financial, and information flows connect participants in both directions" (Fiala, 2005). According to Auramo, et al. (2004), there is a paucity of studies related to IT Use within the Supply Chain Context. Accordingly, their definition is based on referring to the Use of IT, and reflects on the use of interorganizational systems employed for information sharing/processing across organizational boundaries. They found that IT Use can be subdivided into three categories: Transaction Processing, Supply Chain Planning and Collaboration, as well as Order Tracking and Delivery Coordination. Generally, the reduction of manual work, costs reductions, business continuity, and improvement of information quality acted as drivers for the first category. Implementation of cross-organizational processes acted as a driver for the second. Finally, project orientation of business and in-transit consolidation were found to drive the third category. IT Use has been found to be attributable to multiple goals along the Supply Chain, such as management support, reduction in operationalization costs, and gaining in competitive advantage (Subramani, 2004). Dyer and his colleague (2000) contended that a "production network with superior knowledge transfer mechanisms among suppliers, manufacturers, and users, will be able to "out-innovate" networks with less effective knowledge-sharing routines'. This corresponds with the view of Teece et al. (1997) who contended that the continuous ability of a firm to learn, adapt and upgrade its capabilities can be integral to competitive success.

Since knowledge sharing is important in the use of IT, the term should be defined. Knowledge, per se, can be subdivided into two types: Explicit Knowledge (Information), and Tacit Knowledge (Know How). The former reflects easily transferrable, identifiable, codified knowledge, which can be communicated without loss of integrity of content. The latter is indicative of the opposite, where the knowledge is more complex, difficult to codify and not easily transferred (Dyer, and Nobeoka, 2000). Of these two, Tacit Knowledge is more valuable for suppliers because this form of knowledge is harder to communicate. Understandably, there are problems related to knowledge sharing - especially Tacit Knowledge, when applicable to supply chains. Some of them can be resolved by encouraging suppliers to openly share information, and demonstrating how they can realize significant benefits when they participate. Others entail the development of an interconnected, strong-tie network with a variety of processes to facilitate knowledge transfer.

One of the key issues for communication and knowledge sharing along a supply chain is the creation of a shared identity, such as those found in networks, where the relative costs of sharing knowledge is lowered. When this occurs, a 'cooperative social community' results in which competitive advantage is enhanced due to rapid transfer of information, improved collaboration, and increased diversity of knowledge (Dyer and Nobeoka, 2000). In effect, it is more advantageous for a firm to participate in such a setting. Toyota created a supplier association to reduce barriers, encourage the exchange of technical information between their firm and suppliers. One of the primary thrusts of doing this is information sharing and exchange.

The importance of information exchange is paramount along a supply chain. Kim et al. (2006) note the importance of IT enabling firms to accomplish effective/efficient communication with channel partners. When this takes place competitive advantage is enhanced due to an overall lowered cost, inventory reduction, product postponement, more flexible adaptation to market conditions, and quicker response to consumer requirements. The authors of the study further stress the importance of Supply Chain Communication Systems (SCCS), as a key element of Supply Chain Management Systems (SCMS), which is directly related to the various channel partners. IT adoption for SCCS can be defined as the extent to which a firm adopts the most advanced available technology for SCCS, integrates a proactive adoption of state-of-the-art IT to build new technical solutions for SCCS (Kim, Cavusgil, and Roger, 2005). Additionally, they found that information exchange is the most obvious and immediate outcome in SCCS applications. Notably, SCCS integrates elements of IS for better competitive advantage, which operates as a bundle 
of IT software and hardware in focusing on the achievement of corporate goals. Further, Kim et al. (2006) contend that IT is used for communication and is based on hardware and software. They found that firms can more easily gain a sustainable competitive advantage by utilizing SCCS innovations, as well as developing improved channel functions, such as information exchange. Channel functions include sharing of plans for market innovations, development and performance.

\subsection{Resource-Based View}

The basic premise, according to Bharadwaj (2000), of the Resource-Based View is that each firm possesses one, or more unique corporate resources that are valuable, rare and difficult to imitate. Ray et al. (2004) concur with this, and add that resources which are costly to imitate tend to offer the best potential for Competitive Advantage. They contend that a Resource-Based View (RBV) encompasses deployment of valuable resources and capabilities of a firm effectively enhancing sustainable competitive advantage. These terms seem to be used interchangeably in the literature. Specifically addressing RBV, the concept is based on the following logistics: (1) development of a set of measures of a firm's resources and capabilities; (2) establish criteria for evaluation of measures based on existing literature for generating sustainable competitive advantage; correlate the measures with measures of firm performance (Barney, and Arikan, 2001). Resources typically refer to both the tangible and intangible assets employed for strategy implementation. Understandably, only reflecting on a firm's overall performance is not sufficient when examining RBV because Competitive Advantage in one business process may be offset by Competitive Disadvantages in another, either within the same firm, or along the same supply chain.

\subsection{Information Technology (IT) Use}

Currently, information technology is an important factor at every point in the supply chain. Effective use of IT transforms the methods used to exchange related activities and the nature of the linkages among supply chain partners (Chi, J.Y. and Sun, L. 2015). The inter-organizational systems are important because they enable the focal organization to process the needed transformation to create effective networks (Christiaanse \& Kumar, 2000). Moreover Radstaak and Ketelaar 1998), argued that the use of IT improves the efficiency of the supply chain by providing precise and real-time information about production requirement, product availability, shipment status, and inventory level. Also, Karoway (1997) states that effective IT use should facilitate collaborative planning processes within the supply chains. Such facilitation will be performed by sharing more information about production schedules and demands forecasts that organize the activities of the supply chain.

\subsection{Information Sharing}

Information Sharing, amongst organizations, can occur in different levels, such as transactional, operational, and strategic. Transactional information is typically relegated to the category of public information. Operational information is considered what is found between neighboring partners. Strategic information encompasses one of the most sensitive (sometimes proprietary) types of information (Zhou and Benton 2007), reflect on three aspects of Information Sharing: Information Sharing Support Technology (hardware/software), Information Content (shared information amongst manufacturers and consumers), and Information Quality. According to Li, et al. (2006), information sharing is integral to supply chain success because the flow of it throughout the partners facilitates supply and demand linkage, as well as enabling the suppliers to better accommodate changes in consumer demands. Lee et al. (1997) noted that the Bullwhip Effect is reduced with corresponding information sharing and cooperation amongst supply chain partners.

\subsection{Supply Chain Practices}

These practices refer to a set of activities undertaken in a firm to promote effective performance of its supply chain. The literature describes SC practices from different perspectives with a common goal of ultimately improving organizational performance. There are three categories of supply chain practice - JIT production, supply chain planning, and delivery practice. Tan et al (2002), in their empirical study, included quality, purchasing and customer relations to represent SCM practices. Alvarado and Kotzab (2001) included use of inter organizational systems (e.g. Electronic Data Interchange), and elimination of excess inventory levels by postponing customization to the supply chain end.

\subsection{Competitive Advantage}

Competitive advantage is the level at which a firm is able to create a defensible position over its competitors (Porter, 1985). It consists of capabilities that enable a firm to differentiate itself from competitors, based on management decisions. By reviewing the empirical literature, it has been found that price/cost, quality, flexibility and delivery offer significant competitive capabilities (Li, 2007). Correspondingly, current research has included time-based 
competition as a significant competitive priority. In reviewing previous literature, (Greis, N.P. and Kasarda, J.D., 1997) illustrated the framework of the research for competitive capabilities and define the following five dimensions: competitive pricing, value-to-customer quality, premium pricing, production innovation, and dependable delivery, with several studies describing them. Essentially, the dimensions of the competitive advantage construct used in this research are competitive pricing, value-to-customer quality, premium pricing, production innovation, and dependable delivery.

\section{Research Methodology}

The novelty of this paper is to combine three aspects: IT Use, Information Sharing, and Supply Chain Practices, and then reflect on them as they relate to the firms' market performance and financial benefits. It is argued that the previous research has focused primarily on one aspect in discussing the potential factors that could affect supply chain practices, either by focusing on Information Sharing or IT investment only. Notably, there was a lack of discovery related to finding a relationship between the IT Use and Supply Chain Practices. However, this research considers both aspects (IT Use and Information Sharing) and connects them to the firm's market performance through the impact of the supply chain practices. The relationships within supply chain partnerships as they relate to IT Use, Information Sharing, Supply Chain Practices (SCP), with specific reflection on the link between Competitive Advantage and Supply Chain Practices can be examined by using quantitative research methodology. The Research Model is exhibited in Figure 1 and following hypothesis are proposed for the research.

Hypothesis 1: High levels of IT Use will enhance the effectiveness of Supply Chain Practice performance

Hypothesis 2: High levels of IT Use will improve the effectiveness of Information Sharing

Hypothesis 3: Active Information Sharing will enhance Supply Chain Practices performance.

Hypothesis 4: High levels of Supply Chain Practice performance will improve the level of Competitive Advantage.

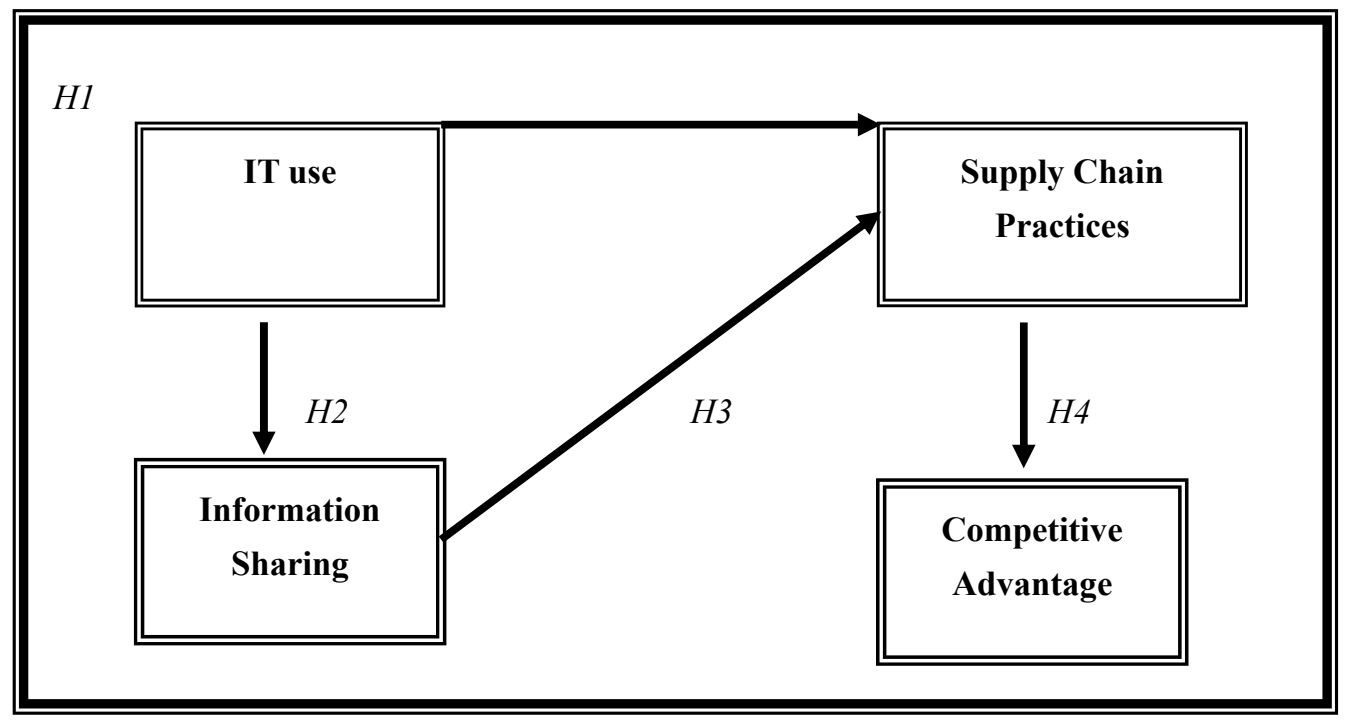

Figure 1. Research framework

The population of the survey will be supply chain managers, and CIOs in firms. The target sample is considered appropriate because it comprised of individuals who are involved in supply chain activities and IT projects. Therefore; those individuals are likely to have supply chain and IT experiences. Also, targeting this level of informant will help us to get valuable information about the competitions.

Questionnaires will be sent out to all respondents requesting information on the IT Use, Information Sharing, and their impact on the supply chain practices performance. Both mail and a web surveys will be used to collect data and test the research hypotheses. The web survey method will be used because computer technology allows the researchers to efficiently collect data better than utilizing a traditional mail survey. The web survey also allows 
researchers to obtain essential data more cost-effectively than the traditional mail survey. The combined use of both mail and web surveys should increase the response rate. Steps will be applied in the survey designing stage to not only improve response rate, but also reduce the potential systematic errors.

Many previous studies of supply chain practices have measured this construct using multiple items, however, in contrast this research uses a minimum of five items derived from the literature: (1) Strategic Supplier Partnership, (2) Customer Relationship, (3) Level of Information Sharing, (4) Quality of Information Sharing, and (5) Postponement. Then Competitive Advantage will be measured by: (1) Cost and Price, (2) Quality, (3) Time-to-Market, (4) Product Innovation and (5) Delivery Dependability. Finally, Information Sharing will be measured on the following dimensions: Information Accuracy, Information Availability, Real-Time Information, Internal Connectivity, External Connectivity, Updating Information Frequently, Information Completeness, and Information Relevance and Information Accessibility. At least 4 items will be developed and adapted in measuring the IT Use construct: (1) Cost Reduction, (2) Management Support, (3) Strategic Planning, and (4) Competitive Thrust. All the items are appropriate in supply chain practices context. Therefore, all the items will be selected and modified for the purpose of this research. The items will be measured based on a seven-point Likert scale from (1) strongly disagree to (7) strongly agree. This study uses generally-accepted statistical analyses: reliability, unidimensionality, convergent, and discriminant validity of the scales.

\section{Expected Results and Conclusions}

The expected results from this research will greatly enhance the understanding of the effective use of IT, the impact on the supply chain practices, as well as linking effective IT use to competitive Advantage. This study should provide a clear definition and understanding of what effective IT uses is in relation to not only supply chain practices, but also competitive advantage. Notably, this research will attempt to discover the impact of IT (Use) on Information Sharing while providing a comprehensive framework embedded within IT Use, Information Sharing, Supply Chain Practices, and Competitive Advantage. Results of this research will provide enhanced operational benefits for both the practitioners and researchers in the field of IT and supply chain management, with respect to IT Use.

\section{Recommendations}

This paper is a conceptually driven with a comprehensive framework and hypotheses are suggested, therefore it is recommended that empirical data can be collected from any selected cluster to prove or disprove the hypotheses. The future research might use the qualitative as well as quantitative research methodologies individually or using a mixed methodology by combining both these methodologies.

\section{References}

Alvarado, U. Y., \& Kotzab, H. (2001). Supply chain management: the integration of logistics in Marketing. Industrial Marketing Management, 30(2), 183-98.

Auramo, J., Inkilainen, A., Kauremma, J., Jaruemaa, J. Kemppainen, K., Karkkainen, M., .. Tanskanen, K. (2004). The Roles of Information Technology in Supply Chain Management. Logistics Research Network Annual Conference, Dublin, Ireland, September, pp. 1-16.

Barney, J., \& Arikan, A. M. (2001). The Resourced-Base View: Origins and Implication. In Handbook of Strategic Management (pp. 124-188). Blackwell: Oxford, U.K.

Bharadwaj, A. S. (2000). A Resource-Based Perspective on Information Technology Capability and Firm Performance: An Empirical Investigation. MIS Quarterly, 24(1), 169-196.

Chi, J. Y., \& Sun, L. (2015). IT and Competitive Advantage: A Study from Micro Perspective. Modern Economy, 6, 404-410.

Christiaanse, E., \& Kumar, K. (2000). ICT-enabled coordination of dynamic supply webs. International Journal of Physical Distribution and Logistics Management, 30(3/4), 268-285.

Dothang Truong. (2015). Efficiency and Risk Management Models for Cloud-Based Solutions in Supply Chain Management. International Journal of Business Analytics, 2(2), 14-30.

Dyer, J. H., \& Nobeoka, K. (2000). Creating and Managing a High-Performance Knowledge-Sharing Network: The Toyota Case. Strategic Management Journal, 21, 345-367.

Fiala, P. (2005). Information Sharing in Supply Chains. Omega - The International Journal of Management Science, $33,419-423$. 
Henderson, J. C. (1990). Plugging into Strategic Partnerships: The Critical IS Connection. Sloan Management Review, 31(3), 7-18.

Hong, K. K., \& Kim, Y. G. (2002). The critical success factors for ERP implementation: an organizational fit perspective. Information and Management, 40(1), 25-40.

Karoway, C. (1997). Superior supply chains pack plenty of byte. Purchasing Technology, 8(11), 32-35.

Kim, D., Cavusgil, S. T., \& Calantone, R. J. (2005). The Role of Information Technology in Supply-Chain Relationships: Does Partner Criticality Matter? Journal of Business \& Industrial Marketing, 20(4/5), 169-178.

Kim, D., Cavusgil, S. T., \& Calantone, R. J. (2006). Information System Innovations and Supply Chain Management: Channel Relationships and Firm Performance. Journal of the Academy of Marketing Science, 34(1), 40-54.

Lee, H. L., Padmanabhan, S., \& Whang, S. (1997). Information Distortion in a Supply Chain: The Bullwhip Effect. Management Science, 43(4), 546-558.

Li, S. (2006). The impact of supply chain management practices on competitive. Omega -The Journal of Management Science, 34, 108.

Li, X., \& Chandra, C. (2007). A knowledge integration framework for complex network management. Industrial Management \& Data Systems, 107(8), 1089-1109.

Porter M. E. (1985). Competitive advantage: creating and sustaining superior performance. New York: The Free Press.

Radstaak, B. G., \& Ketelaar, M. H. (1998). Worldwide Logistics: The Future of Supply Chain Services. Holland International Distribution Council, Hague, The Netherlands.

Ray, G., Barney, J. B., \& Muhanna, W. A. (1997). Capabilities, Business Processes, and Competitive Advantage: Choosing the Dependent Variable in Empirical Tests of the Resource-Based View. Strategic Management Journal, 25, 23-37.

Subramani, M. (2004). How Do Suppliers Benefit from Information Technology Use in Supply Chain Relationships?. MIS Quarterly, 28(1), 45-73.

Tan, K. C., Lyman, S. B., \& Wisner, J. D. (2002). Supply chain management: a strategic perspective. International Journal of Operations and Production Management, 22(6), 614-631.

Teece, D. J., Pisano, G., \& Shuen A. (1997). Dynamic Capabilities and Strategic Management. Strategic Management Journal, 17, 509-533.

V. Botta-Genoulaza, P. A. Milleta, \& B. Grabotb. (2005). A survey on the recent research literature on ERP systems. Computers in industry, 56(6), 510-522.

Zhou, H., \& Benton, W.C., Jr. (2007). Supply chain practice and information sharing. Journal of Operations Management, 25, 1348-1365. 